\title{
Relative contribution of central and peripheral factors in superficial blood flow regulation following cold exposure
}

\author{
Somayeh Nazari ${ }^{1}$, Masoumeh Kourosh-Arami* iD, Alireza Komaki ${ }^{3 *}$ iD), Sohrab Hajizadeh ${ }^{4}$ \\ 1. Department of Physiology, Medical College, Shiraz University of Medical Sciences, Shiraz, Iran \\ 2. Department of Neuroscience, School of Advanced Technologies in Medicine, Iran University of Medical Sciences, Tehran, \\ Iran \\ 3. Neurophysiology Research Center, Medical College, Hamedan University of Medical Sciences, Hamedan, Iran \\ 4. Department of Physiology, Medical College, Tarbiat Modares University, Tehran, Iran
}

\begin{abstract}
The aim of the present study was to evaluate the extent of contribution of thermal regulators in cold stress. Hypothermia is described as a diminution in core body temperature below $35^{\circ} \mathrm{C}$. Thermoregulation is the equilibrium between heat generation (thermogenesis) and heat loss (thermolysis). Thermoregulatory control of skin blood flow (SBF) is critical to preserve body temperature homeostasis during thermal changes. The obtained results from different studies revealed that following cold exposure, some areas of the brain like preoptic/anterior hypothalamus, known as body thermostat, involve in thermoregulation by affecting on SBF. Furthermore, some peripheral factors participate in the thermal control through alteration of skin blood flow. Sympathetic neural control of SBF includes the noradrenergic vasoconstrictor system and a sympathetic active vasodilator system. Overall, further future studies are required to elucidate the imbalance of these regulators in some disorders.
\end{abstract}

http://dx.doi.org/10.32598/ppj.24.2.50

\section{Keywords:}

Hypothermia;

Skin blood flow;

Thermoregulation

* Corresponding authors:

Masoumeh Kourosh-Arami

Alireza Komaki

Emails:

kourosharami.m@iums.ac.ir

Komaki@umsha.ac.ir

Tel: +98 (21) 86704788

Received 4 December 2019;

Received in revised form 7

February 2020; Accepted 2

March 2020

\section{Introduction}

Body temperature, usually reflects the central core and peripheral shell temperatures. The core temperature refers to the temperature within the "deep" body tissues with a high level of basal metabolism (including the heart, brain and liver). The shell temperature refers to skin blood flow (SBF), which is elevated with a high core temperature and environmental temperature. The surface area-tomass ratio of end organs is high (Taylor et al., 2014), that is important for the thermal energy transmission. During cold stress, skin blood flow is diminished, resulting in a decrease in shel I temperature and conservation of heat to the core. Temperature gradients between the core and skin can be a beneficial nonspecific monitor of thermal status. The hypothalamus is the coordinating or central integration center for thermoregulation. Evidence suggests that preoptic anterior hypothalamus is the most important region for autonomic temperature control (Romanovsky, 2007).

Human physiological thermoregulation refers to four mechanisms: sweating, shivering, vasodilation and vasoconstriction. This active equilibrium, which maintains body temperature near $37^{\circ} \mathrm{C}$, permits the 
enzyme systems to operate within a narrow optimum activity. Major studies have focused on assessing SBF in response to hypothermia. In state of mild hypothermia, the thermoregulatory mechanisms function at a maximum in an attempt to combat heat loss, with trembling (shivering), cutaneous vasoconstriction, reduced peripheral perfusion, increase cerebral blood flow and blood pressure. Cutaneous vasodilation and sweating in exercise and heat exposure are important for heat loss. During cold exposure, skin blood vessels constricted to reduce heat loss and protect from hypothermia. Therefore, alteration of skin blood flow has important clinical implications and can suppress the mechanism of heat balance (Charkoudian, 2003). The temperature of body core is maintained within a very small range by the balance between heat loss and gain. The main function of posterior hypothalamus and its functional relations with the anterior hypothalamus in thermoregulation is to integrate temperature signals reaching from cold and warmsensitive nerve endings located on the skin, through the sympathetic nerve system. Since skin has more cold sensors than warm that are closer to the surface, so it has the rapid detection of cold than of warmth (Arens and Zhang, 2006).

During menopause, changes in reproductive hormone levels make alterations in thermoregulation control of skin blood flow that might contribute to the occurrence of hot flashes (Brooks and Kenney, 1997). In type 2 diabetes mellitus, the ability of skin blood vessels to dilate is impaired that contributes to the increased occurrence of heat illness during exposure to increased ambient temperatures (Semenza et al., 1999; Kenney et al., 2014). We will consider three questions: What induces thermoregulation center? What determines its direction and magnitude? What are some possible functions of skin in physiological thermoregulation? In this review, we will discuss the normal processes of the human physiological thermoregulation, as well as central regulatory control of SBF including sympathetic vasoconstrictor control and nitric oxide (NO) involvement. In the following, we will introduce important peripheral factors in SBF regulation including hormonal responses like renin-angiotensinaldosterone system that results in control of blood pressure in hypothermia. Also, we will focus on the blood-derived thermoregulatory factors. Finally, we will describe the clinical perspectives of cold exposure.

Overview of the role of the skin in human physiological thermoregulation

The skin plays a functional role in the thermoregulatory process. In response to increased or decreased internal temperature, SBF is altered by sympathetic vasodilation and vasoconstriction mechanisms, respectively (Tansey and Johnson, 2015). When vasoconstriction happens in response to cold, then blood is shunted away from the skin surface through the deeper veins. Heat is thus saved, and a spreading of the gradient between core and peripheral temperature occurs. In response to cold, sympathetic vasoconstrictor nerves act mainly on $\alpha$ noradrenergic receptors to make blood vessel smooth muscle contraction and vasoconstriction. Other sympathetically released co-transmitters also contribute to this vasoconstriction, such as ATP and neuropeptide Y (Stephens et al., 2004; Romanovsky, 2007).

Human physiological thermoregulation contains alteration in heat loss via cutaneous vasodilation and sweating and heat production via shivering in response to various internal and external thermal stimuli. The preoptic/anterior hypothalamus in the brain is the thermoregulatory center that receives direct or indirect thermal information from internal (core) and superficial (skin) receptors. This area then processes the temperature information and relays via efferent neural pathways (Boulant, 2010; Boulant, 2000). This region of hypothalamus acts as a thermostat which initiates heat loss and heat gain responses when the temperature is remarkably low or high. The route of thermoregulation by the preoptic/anterior hypothalamus is shown in Figure 1 (Charkoudian, 2003).

Skin blood flow at rest in normothermic environments is about $250 \mathrm{ml} / \mathrm{min}$, which makes 80 to $90 \mathrm{kcal} / \mathrm{h}$ of heat loss, about the level of resting metabolic heat production (Johnson et al., 1986a; Johnson and Proppe, 1996). Main physiological responses to lose heat during exercise are cutaneous vasodilation and sweating (Johnson, 1992; Johnson and Proppe, 1996). Cutaneous vasodilation and sweating during exercise increases blood flow to the skin via augmented cardiac output and displaces blood flow through splanchnic vasoconstriction without 


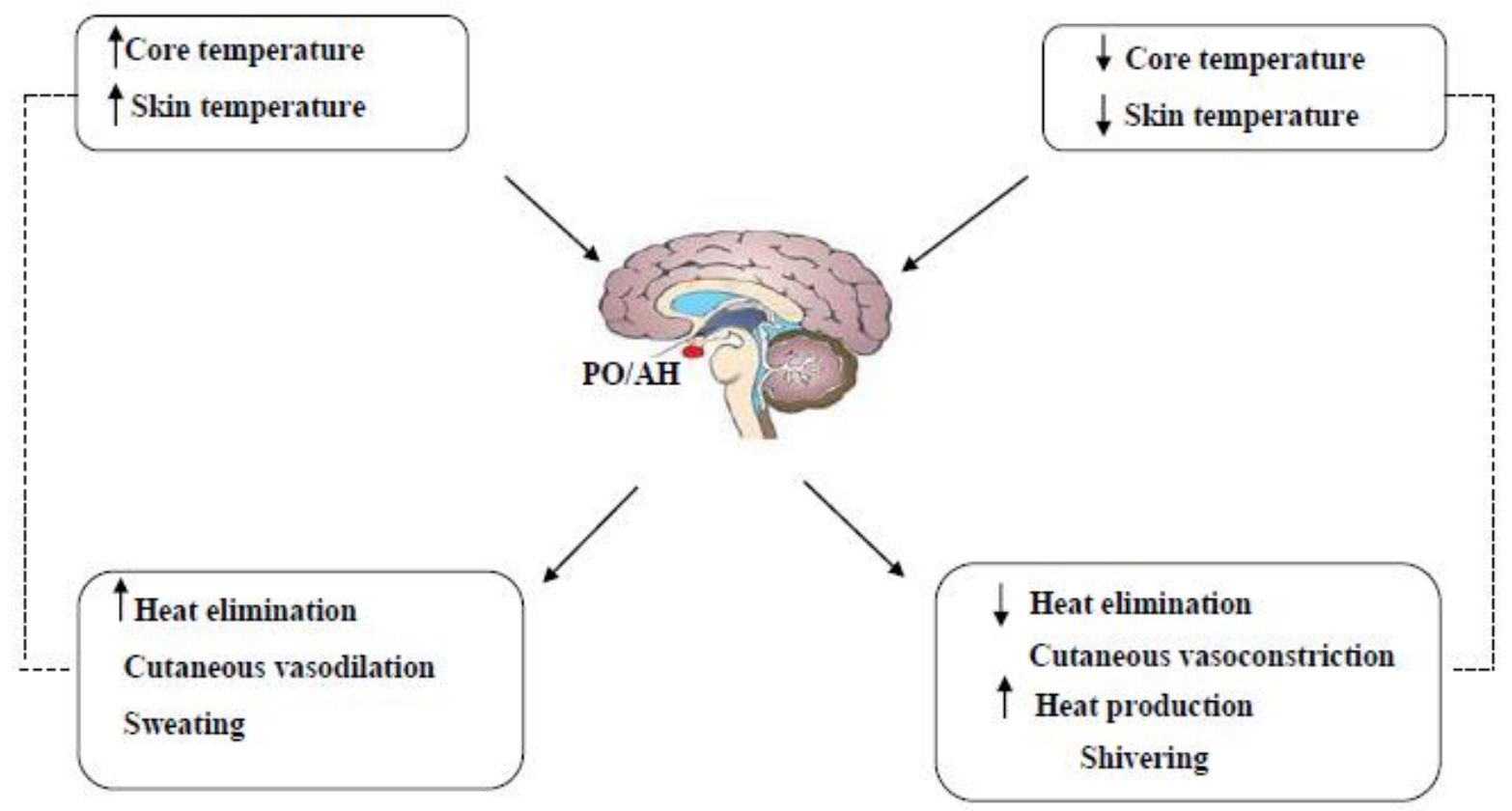

Fig.1. Thermoregulatory loop by involvement of hypothalamus. Dotted line shows the modification of error signal (change in skin and/or internal temperature) by the suitable effector response. Preoptic/anterior hypothalamus (PO/AH) gather information about rising of internal and/or skin temperatures and then makes augmented heat loss via cutaneous vasodilation and sweating, to adjusts the initiated changes. Diminished skin or internal temperature via reflex decreases heat loss (cutaneous vasoconstriction) and augmented heat production (shivering), adjusts the first changes (Charkoudian, 2003).

consistent alterations in oxygen supply to the organs such as heart but sufficient to match the demand of amplified skin blood flow (Johnson and Proppe, 1996).

Furthermore, the evaporation of sweat reduces skin temperature as well as cutaneous vasodilation. Hence, skin blood flow and sweating continue to increase until a heat balance is reached at which the rate of heat generation is equal to the heat loss. Internal temperature drops and then returns to normal level, when cutaneous vasodilation and sweating cause cooling of the blood. This mechanism defined as classic negative feedback (Fig. 1; Charkoudian, 2003). In negative control increment of core temperature leads to cutaneous vasodilation to reduce the core temperature.

In other study, it is revealed that the lateral parabrachial nucleus (LPB) receives spinal input from cold-sensitive neurons. Third-order LPB neurons ascend from these areas, which then project to the median preoptic nucleus and then median preoptic nucleus (MPO). Activation of these pathways will recruit heat gain process (Fig. 2; Tansey and Johnson, 2015). One of the neuropeptides that involves in thermoregulation is orexin. Orexin neuropeptides that are produced in the lateral part of the hypothalamus area activate postsynaptic neurons via two G-protein coupled receptors (Babasafari et al., 2019; Rezaei et al., 2020). Administration of orexin A activates thermogenesis, without limiting feeding or increasing physical activity (Messina, Dalia et al. 2014).

Cutaneous vasodilation and sweating begin at internal temperature thresholds (Johnson, 1992; Johnson and Proppe, 1996). Furthermore, the slope of skin blood flow-internal temperature relationship is considered as the gain or sensitivity of the sweating or vasodilator response. For example, lower skin blood flow at a given level of internal temperature during heat stress could be due to active vasodilator activity that is initiated in higher internal temperatures (an increased threshold for vasodilation), in a decrement of the response sensitivity or combination of both (Charkoudian, 2003). Factors influencing on the threshold and/or sensitivity of cutaneous vasodilation are heat adaptation, exercise training (Roberts et al., 1977), circadian rhythm (Stephenson and Kolka, 1985; Aoki et al., 2001) and reproductive hormone level (Brooks and Kenney, 1997; Charkoudian and Johnson, 1997; Charkoudian and 


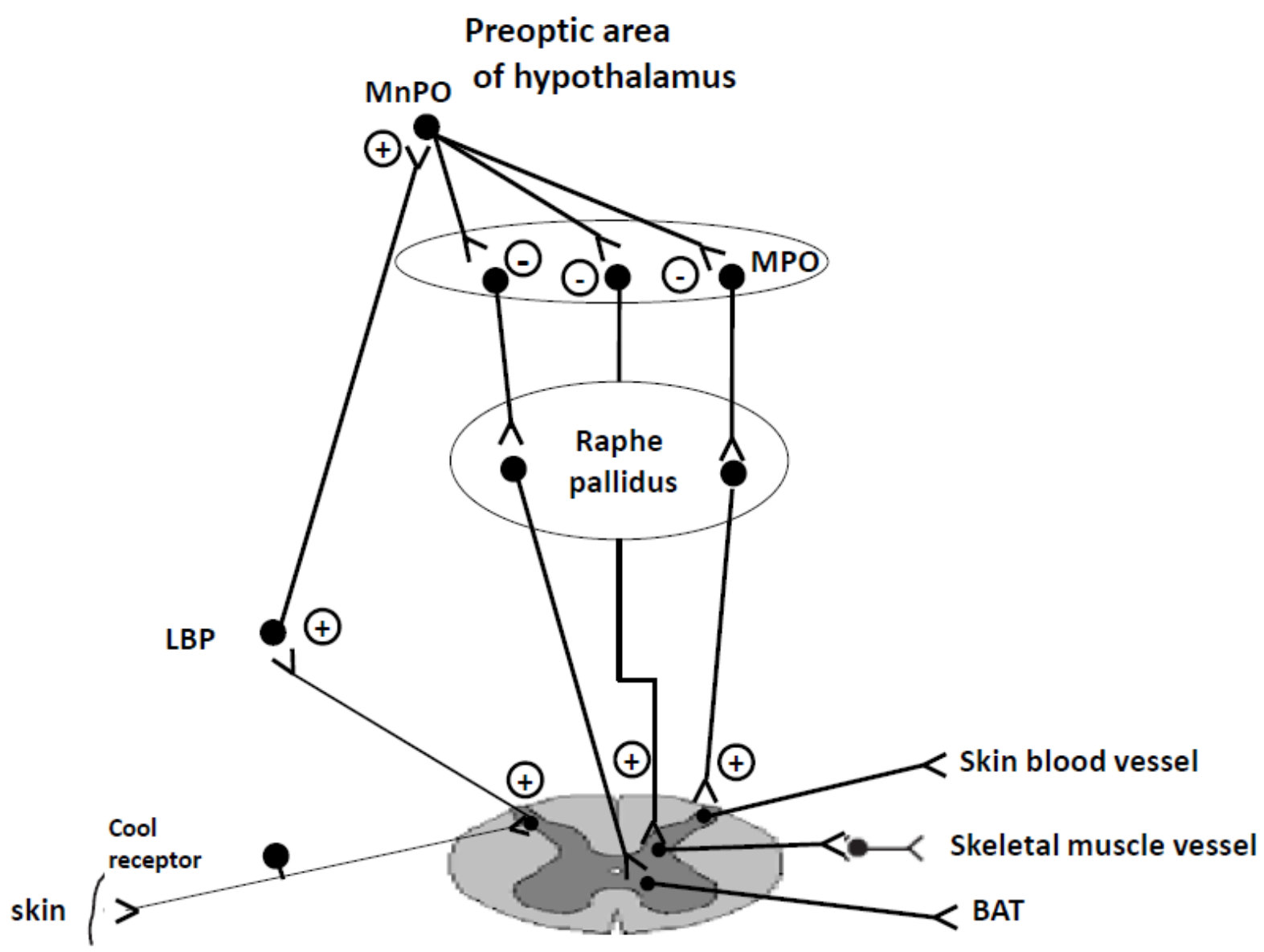

Spinal cord

Fig.2. Central thermoregulation circuitry in response to cold. The lateral parabrachial nucleus (LPB) receives spinal input from cold-sensitive neurons. Third-order LPB neurons ascend from these areas, which then project to the median preoptic nucleus (MnPO) and then median preoptic nucleus (MPO). Activation of these pathways will recruit heat gain process (Tansey and Johnson, 2015).

Johnson, 1999b).

Skin blood flow reduces through cutaneous vasoconstriction when the person is exposed to cold temperatures. As the temperature cools down, the shivering starts. Muscle contraction accompanied by vascular contraction with augmentation of heat generation and diminishing heat loss declines heat transfer from the core to the surface and thus conservation of core temperature in the face of cold (Charkoudian, 2003).

Laser doppler flowmetry or venous occlusion plethysmography are two techniques for measurement of skin blood flow (Johnson et al., 1984; Oberg, 1990; Johnson and Proppe, 1996). Laser doppler measurement of SBF is based on the fact that a laser light beam incident on tissue is dispersed in static structures as well as in moving red cells and then shift based on the doppler effect (Oberg, 1990). This method has several advantages. It is specific to the cutaneous microcirculation and the signal is constant and has an outstanding frequency response (Saumet et al., 1988; Oberg, 1990). Potential unresolved problems contain weakness of ability to measure absolute flow values (ie, flow is measured in arbitrary laser doppler units or volts rather than in milliliters per minute) and the limitation to a relatively small area of measurement (Charkoudian and Johnson, 1997; Kellogg et al., 1998; Charkoudian and Johnson, 1999a).

Venous blocking plethysmography can be exerted to evaluate blood flow in the limbs including forearm, lower leg or finger. In the forearm or the lower leg, it is usually used to assess deviations in skin blood flow in circumstances in which blood flow to underlying muscle does not alter (ie, passive heat stress). In the finger, both glabrous and nonglabrous skin blood flow is measured which can limit interpretation, depending on the issues being addressed. The advantage of this method is the measurement of the total alterations in SBF but the disadvantage is that measurements 


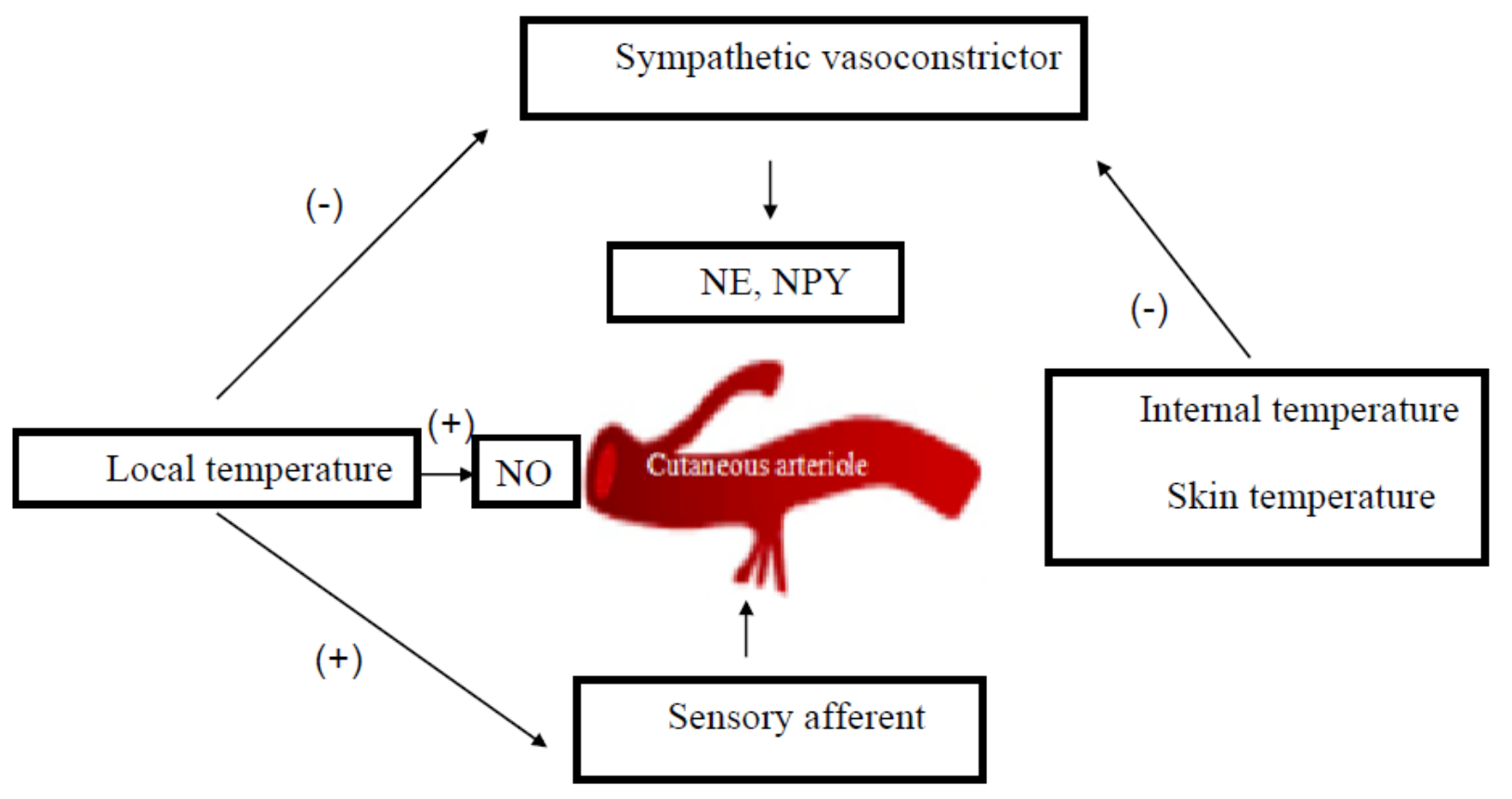

Fig.3. Local reductions in temperature make vasoconstriction by the release of norepinephrine (NE) and neuropeptide $Y$ (NPY). Local warming stimulates sensory nerves to make vasodilation and then resultant NO causes vasodilation in the slower phase. Plus and minus signs are positive and negative effects, repectively. Any rises in temperature reduces activity and vice versa (Kourosh et al., 2005; Charkoudian, 2003).

cannot be taken uninterruptedly and not being specific to the skin (Charkoudian, 2003).

\section{Contribution of central factors in skin blood flow regulation}

\section{Thermoregulatory center and skin blood flow}

The greatest amount of thermoresponsive neurons were initiated in the nucleus raphe magnus (NRM) (Dickenson, 1977). Previous studies have shown that the medullar raphe is important in the rat tail blood flow (TBF) regulation which is the chief organ of heat loss in this species (Rathner and McAllen, 1999; Asahina et al., 2003). Sudomotor and vasomotor responses to alteration of environmental temperature are important in thermoregulation by the NRM through regulation of the SBF (Berner et al., 1999; Korsak and Gilbey, 2004). Previous studies have reported that electrical stimulation of mid to caudal raphe magnus produced an increase of sweat secretion and SBF in forepaw pads of decerebrate cats (Asahina et al., 2003; Malakouti et al., 2008).

Excitation of the raphe neurons mediates fluctuations in the cutaneous bed without affecting arterial pressure and altering blood pressure in the mesenteric bed (Blessing and Nalivaiko, 2000; Nalivaiko and Blessing, 2002). In another study in anesthetized hyperthermic rats, chemical stimulation of rostral ventrolateral medulla could diminish tail temperature (Key and Wigfield, 1992). Evidence shows the contribution of medullar raphe in the control of rat tail blood flow. Labeled sympathetic premotor neurons are recognized in the medullary raphe nuclei following tracer injection into tail artery (Smith and Gilbey, 1998). Excitatory neurons in the medullary raphe nuclei were found to be a novel group of sympathetic premotor neurons for thermoregulatory function (Nakamura et al., 2004). A rising of Fos expression immunoreactivity was shown in the raphe following cold exposure (Tanaka et al., 2002). In our previous study, injection of lidocaine (the fast activity anesthetic agent, block sodium channels) interrupt local neuronal activity in the NRM (Kourosh Arami et al., 2006). In hypothermia, lidocaine injections into the medullary raphe result in suppressing the tail vasoconstriction and thus, lidocaine inhibits the thermoregulatory effect of NRM and decreases TBF (Kourosh Arami et al., 2006).

During cold exposure, cutaneous vasoconstriction reduces heat loss and protect from hypothermia. Therefore, alteration of skin blood flow has important clinical implications and can weaken the mechanism of heat balance. In our previous study, microinjection of lidocaine into nucleus raphe magnus significantly decreased TBF. Therefore, we concluded that the 
NRM has thermoregulatory effect in response to hypothermia (Malakouti et al., 2008). In next step, to find the underlying mechanism of NRM in TBF regulation we examined the effect of nitric oxide donor and inhibitor. In that research we indicated that injection of sodium nitroprusside (exogenous NO donor) into NRM results in the elevation of blood flow. According to our previous study, when TBF reduced in response to hypothermia the injection of glutamate in the raphe magnus resulted in increases in blood flow of tail cutaneous bed. It is proposed that glutamate by a reduction in sympathetic outflow may be responsible for its hypothermic action in the NRM. So, our work highlights the importance of interaction between glutamate and thermoregulatory pathway in the nervous system (Kourosh Arami et al., 2006). However, further investigations are thought to be necessary in order to evaluate the thermoregulatory action. In the next step, we found that this effect of Lglutamate was reduced by prior intra NRM administration of nitric oxide synthase inhibitor (LNAME) (Arami et al., 2015). Therefore, NO in the nucleus raphe magnus may interact with excitatory amino acids and modulate cutaneous blood flow in rats. Evidence shows that hypertension may decrease the skin blood flow. Moreover, in other set of our studies, we found that the renin, angiotensin and aldosterone levels were increased in response to hypothermia. Activation of renin and so angiotensin may increase blood pressure and hence may decrease the skin blood flow. In addition, aldosterone elevation in hypothermia may increase the blood pressure by the maintenance of sodium and water that will lead to skin blood flow decrement (Kourosh et al., 2005).

\section{Vasoconstrictor control of skin blood flow by sympathetic nervous system}

The vasoconstriction is a manner to control the skin circulation (Edholm et al., 1957). The sympathetic vasoconstrictor nerves innervate glabrous skin including palms, soles and lips (Johnson and Proppe, 1996). In glabrous skin, arteriovenous anastomoses (AVA) which are low resistance pathways can alter flow rates directly from arterioles to venules through opening or closing of these AVA (Lossius et al., 1993). AVA is the elaborate system in rats tail that regulates heat dissipation by sympathetic regulation during hypothermia (Blessing and Nalivaiko, 2001).
The skin vasoconstrictor activity is regulated by the sympathetic nervous system and depends on both core and skin temperatures. Cooling the skin initiates an increased vasoconstrictor nerve activity, the release of norepinephrine and NPY which interacts with postsynaptic $\alpha 1$ and $\alpha 2$ receptors on cutaneous arterioles and AVA and a reduction in skin blood flow (Fig. 3; Stephens et al., 2001; Stephens et al., 2002; Smith and Johnson, 2016). In response to cold temperature, thermoregulatory vasoconstriction can limit the skin blood flow by variation of the vasoconstrictor outflow to cutaneous arterioles and particularly arteriovenous anastomoses, a countercurrent exchange of heat to further reduction of heat loss (MacKenzie et al., 1996). The vasoconstrictor system in human skin is characteristically active at normal brain and skin temperatures (Pergola et al., 1994). This system is responsible for the protection of normal body temperature. Delicate changes in skin or body temperature are equal to minor changes in skin blood flow and heat elimination and hence, body temperature remains in a very narrow range (Smith and Johnson, 2016).

\section{Vasodilator control of skin blood flow by nitric oxide}

NO, as a prominent second messenger, plays an important role in thermoregulation in the central and peripheral nervous systems (Leger et al., 1998). NO as a central activator of heat defense mechanism is synthesized in all mesencephalic raphe nuclei cells (Leger et al., 1998). In our previous study, we found that injection of sodium nitroprusside into NRM prevents thermal vasoconstriction of rat tail vessels in response to cold exposure but the injection of LNAME, known as an inhibitor of nitric oxide synthase, disrupts the excitatory effect of glutamate on the NRM and then on TBF (Arami et al., 2015). It has been reported that the creation of $\mathrm{NO}$ and resultant cGMP levels increase by stimulation of NMDA receptors. Furthermore, NO rises the release of excitatory amino acids by cGMP-dependent processes in the dorsomedial medulla (Dias et al., 2007). In a study demonstrated that L- NAME reduced NO facilitation of excitatory amino acidevoked excitation of NTS neurons (Dias et al., 2005). Based on the reports of various studies, administration of NOS blockade (Eriksson et al., 1997; Mathai et al., 2004), or administration of NO 
donor (Mathai et al., 2004), exert a tonic restraint in central sympathetic outflow. Sympathetic fibers play an important role in stimulating vasoconstriction of the superficial vascular beds, so it is probable to propose that a reduction in the sympathetic outflow by $\mathrm{NO}$ in the raphe may be responsible for its thermoregulatory action in the CNS (Arami et al., 2015). Moreover, there are two phases of vasodilation during local warming: a rapid phase and a slower phase. In the first phase, local nervous activity is involved but in the slower phase, NO has an important role in starting and maintaining of this phase so that when local L-NAME is administered prior to local heating, vasodilation is inhibited (Johnson et al., 1986b; Kellogg et al., 1999). During postnatal development, some glutamatergic synapses first contain NMDA receptors (Kourosh Arami, Semnanian et al., 2011, Arami, Hajizadeh et al., 2016), which mainly yield hyperpolarization and inhibitory effects (D'yakonova, 2000). Synchronized application of glutamate and nitroprusside, which is a NO donor, however, established an opposite effect, as cells responded to glutamate with depolarization and excitation.

\section{Contribution of peripheral factors in skin blood flow regulation}

\section{Hormonal thermoregulation of skin blood flow}

The evidence demonstrated that cold air exposure for 3 weeks, increases plasma renin activity and then returns to a normal level. It is also known that plasma renin activity increment in response to hypothermia can result from the effect of sympathetic activation. It is observed that the plasma concentration of norepinephrine increases 30 minutes to an hour after hypothermia and remains elevated during cold exposure (Kourosh et al., 2005). In one study, a significant drop in heart rate, cardiac output, arterial pressure and left ventricular contractility were observed during cold exposure (Talwar and Fahim, 1998). This reduction in arterial pressure stimulates renin secretion by juxtaglomerular cells and thereby activates angiotensin production. Furthermore, a remarkable increment in serum aldosterone level is observed (Kourosh et al., 2005).

In a study, decreased Na-K ATPase pump activity in the corticorenal region in response to cold exposure resulted in rising of aldosterone synthesis and secretion (Johnson et al., 1996; Lee et al., 1996). In an experiment renin-angiotensin stimulation in response to hypothermia induced catecholamine activation and hence increment of $\mathrm{NaCl}$ intake in mice (Dejima et al., 1996). It has been reported that renin-angiotensin is activated in a hypothermic intervention during cardiopulmonary bypass. It was shown that aldosterone level increases in pulsatile and nonpulsatile cardiopulmonary bypass (Sun et al., 1997).

\section{Hypothermia and blood pressure regulation}

Exposure to stress, activates many neurochemical systems. The main physiological response to a stressor is the activation of the hypothalamicpituitary-adrenal axis. A previous study showed that a moderate exposure to the cold, results in systemic activation of the renin-angiotensin-aldosterone system in rats that causes increase of blood pressure associated with lowering the blood flow to the skin, and this problem is gradually getting worse if the hypertension is not treated (Cowburn et al., 2017). A substantial decrease in skin blood flow reserve in chronic hypertension has been shown. This reduction at sites with significant arteriovenous perfusion is greater than at nutritive sites (Rendell et al., 1996). This is another reason for cold-induced reduction of skin blood flow. In one study, exposure to sever cold elevated blood pressure, cortisol, aldosterone and noradrenaline. Administration of dexamethasone significantly reduced increment of aldosterone and cortisol in response to cold but had not any effect on blood pressure and noradrenaline. Therefore, it was concluded that among the various hormones, noradrenaline is the only hormone responsible for an elevation of blood pressure in response to cold (Hiramatsu et al., 1984). The finding of a study demonstrated that whole-body cold stress results in greater increases in sympathetic outflow directed to the cutaneous vasculature and subsequently, greater reductions in skin blood flow in hypertensive adults. Therefore, control of cutaneous vasculature by the sympathetic nervous system is not only preserved, but also exaggerated in hypertension (Greaney et al., 2017).

\section{Blood-derived thermoregulatory factors}

The viscosity of the blood increases with declining temperature. Low temperature affects shear-induced platelet aggregation (Van Poucke et al., 2014). The 
reduction in platelet count observed in vivo returned to a normal level during hypothermia (Van Poucke et al., 2014). A study suggested that platelet-poor plasma is an essential potential activator of angiogenesis (Shahidi et al., 2018). Angiogenesis is a complex process that organizes the formation of blood vessels from the pre-existing vasculature. Skin blood flow can reduce in response to hypothermia. Furthermore, reduction of skin blood flow in hypothermic rats leads to decrease of angiogenesis (Ramasamy et al., 2016). In addition, in angiogenesis, total blood volume of the tissue increased but the rate of flow decreased. This is another reason for the reduction of blood flow in skin vessels. In addition, reduction of skin blood flow may be produced in response to the enhancement of blood viscosity by hypothermia (Van Poucke et al., 2014). Mild hypothermia has been shown to enhance angiogenesis in focal cerebral ischemia (Xie et al., 2007), spinal cord injury (Kao et al., 2011) and traumatic brain injury models (Kuo et al., 2010). Effect of hypothermia on angiogenesis might be diverse in different tissues. Mild hypothermia enhances angiogenesis in the ischemic brain, which might be enhanced in part via brain-derived neurotrophic factor.

\section{Brown adipose tissue}

Brown adipose tissue is involved in non-shivering thermogenesis, where oxidative metabolism is uncoupled from ATP creation and energy is expended. This tissue is thermogenic by augmentation of the metabolic rate. Brown adipose tissue until recently was thought to be only important in small mammals and neonates. Although, evidence shows the stimulation of brown adipose tissue in adult humans in cold exposure (Nedergaard et al., 2007; Saito et al., 2009; van der Lans et al., 2013). Sympathetic nervous system can activate brown adipose tissue thermogenesis. Catecholamines through $\beta_{3}$-adrenergic receptors can stimulate an uncoupling protein on the inner mitochondrial membrane. The uncoupling protein permits $\mathrm{H}^{+}$to transfer across the mitochondrial membrane without ATP making (Klingenspor, 2003).

\section{Shivering}

In hypothermia, animals will save heat by mechanisms including vasoconstriction and piloerection, which are energetically inexpensive and by changes in behavior. If these alterations are inadequate to preserve temperature, shivering occurs. The beginning of shivering shows that maximal vasoconstriction has previously been accomplished (DeGroot and Kenney, 2007). It is started by the hypothalamic preoptic area but mediated by the somatic motor cortex in response to signals from skin cold receptors; hence, the normal stimulus for shivering is temperature of the skin rather than the core temperature (DeGroot and Kenney, 2007).

Shivering is involuntary, fast, oscillating contractions of skeletal muscle. ATP is hydrolyzed, but no work is done by contraction and hence the energy formed is released as heat. In adults, shivering, at its maximum rate, produces heat creation comparable to five times the basal metabolic rate (Eyolfson et al., 2001); though, in neonates, because of immaturity of their skeletal muscles, non-shivering thermogenesis happens (Stern, 1980).

\section{Clinical perspectives}

With menopause, variations in reproductive hormone levels make alternations in thermoregulatory control of skin blood flow. The occurrence of hot flashes may also be caused by this altered control (Brooks and Kenney, 1997). In patients with type 2 diabetes mellitus, impairments in cutaneous vasodilation may contribute to the increased occurrence of heat illness (heat shock, heat exhaustion) during increased ambient temperatures (Semenza et al., 1999; Kenney et al., 2014). There was a markedly decreased cutaneous vasodilation to local iontophoresis of acetylcholine and sodium nitroprusside in diabetes mellitus patients with or without neuropathy (Arora et al., 1998). Impairments of local and/or reflex thermoregulatory control of the skin circulation appears to cause microvascular disorders including Raynaud phenomenon and erythromelalgia. The pathophysiology of these conditions remain unclear, but alterations in local neural mechanisms and neuropeptides and endothelial vasoactive factors contribute to these diseases (Bunker et al., 1996; Alba et al., 2019).

\section{Conclusion}

Specific fundamental mechanisms for hypothermiainduced reduction of skin blood flow discussed in this 
review. Current understanding of skin blood flow control includes important roles for nucleus raphe magnus that have thermoregulatory effect in response to hypothermia. Cutaneous sympathetic vasoconstrictor and renin-angiotensin activation and then aldosterone elevation in hypothermia participate in increasing the blood pressure and skin blood flow attenuation. Furthermore, NO as an important factor in the raphe magnus can modulate central cutaneous blood flow in rats during hypothermia.

\section{Acknowledgments}

The authors wish to thank the Iran University of Medical Sciences for assisting us in conducting this study.

\section{Conflict of interest}

The authors declare that they have no conflict of interests.

\section{References}

Alba BK, Castellani JW, Charkoudian N. Cold-induced cutaneous vasoconstriction in humans: function, dysfunction and the distinctly counterproductive. Exp Physiol 2019; 104: 1202-14. https://doi.org/10.1113/ EP087718

Aoki K, Stephens DP, Johnson JM. Diurnal variation in cutaneous vasodilator and vasoconstrictor systems during heat stress. Am J Physiol Regul Integr Comp Physiol 2001; 281: 591-5. https://doi.org/10.1152/ ajpregu.2001.281.2.R591

Arami MK, Zade JM, Komaki A, Amiri M, Mehrpooya S, Jahanshahi $A$, et al. Nitric oxide in the nucleus raphe magnus modulates cutaneous blood flow in rats during hypothermia. Iran J Basic Med Sci 2015; 18: 989-92.

Arami MK, Hajizadeh S, Semnanian S. Postnatal development changes in excitatory synaptic activity in the rat locus coeruleus neurons. Brain research 2016; 1648: 365-71.

Arens EA, Zhang $H$. The skin's role in human thermoregulation and comfort. In: Pan N, Gibson P, editors. Thermal and moisture transport in fibrous materials. Woodhead Publishing, 2006. https://doi.org/ 10.1201/9781439824351.ch16

Arora S, Smakowski P, Frykberg RG, Simeone LR, Freeman R, LoGerfo FW, et al. Differences in foot and forearm skin microcirculation in diabetic patients with and without neuropathy. Diabetes Care 1998; 21: 133944. https://doi.org/10.2337/diacare.21.8.1339

Asahina M, Kikkawa Y, Suzuki A, Hattori T. Cutaneous sympathetic function in patients with multiple system atrophy. Clin Auton Res 2003; 13: 91-5. https://doi.org/10.1007/s10286-003-0072-z

Babasafari M, Kourosharami M, Behman J, Farhadi M,
Komaki A. Alteration of phospholipase $\mathrm{C}$ expression in rat visual cortical neurons by chronic blockade of orexin receptor 1. Int J Pept Res Ther 2019; 28: 1-7. https://doi.org/10.1007/s10989-019-09943-y

Berner NJ, Grahn DA, Heller HC. 8-OH-DPAT-sensitive neurons in the nucleus raphe magnus modulate thermoregulatory output in rats. Brain Res 1999; 831: 155-64. https://doi.org/10.1016/S0006-8993(99)01426-2

Blessing WW, Nalivaiko E. Raphe magnus/pallidus neurons regulate tail but not mesenteric arterial blood flow in rats. Neuroscience 2001; 105: 923-9. https://doi.org/10.1016/S0306-4522(01)00251-2

Blessing WW, Nalivaiko E. Regional blood flow and nociceptive stimuli in rabbits: patterning by medullary raphe, not ventrolateral medulla. J Physiol 2000; 524: 279-92. https://doi.org/10.1111/j.1469-7793.2000.t01-200279.x

Boulant JA. Hypothalamic neurons regulating body temperature. Handbook of Physiology. Environl Physiol 2010; 105-126. https://doi.org/10.1002/cphy.cp040106

Boulant JA. Role of the preoptic-anterior hypothalamus in thermoregulation and fever. Clin Infect Dis 2000; 31: 157-61. https://doi.org/10.1086/317521

Brooks-Asplund EM, Kenney WL. Chronic hormone replacement therapy does not alter resting or maximal skin blood flow. J Appl Physiol 1998; 85: 505-10. https://doi.org/10.1152/jappl.1998.85.2.505

Bunker CB, Goldsmith PC, Leslie TA, Hayes N, Foreman JC, Dowd PM. Calcitonin gene-related peptide, endothelin-1, the cutaneous microvasculature and Raynaud's phenomenon. Br J Dermatol 1996; 134: 399 406. https://doi.org/10.1111/j.1365-2133.1996.tb16221 $\mathrm{x}$

Charkoudian N. Skin blood flow in adult human thermoregulation: how it works, when it does not, and why. Mayo Clin Proc 2003; 78: 603-12. https://doi.org/ 10.4065/78.5.603

Charkoudian N, Johnson JM. Altered reflex control of cutaneous circulation by female sex steroids is independent of prostaglandins. Am J Physiol 1999a; 276: H1634-40. https://doi.org/10.1152/ajpheart.1999 276.5. $\mathrm{H} 1634$

Charkoudian N, Johnson JM. Modification of active cutaneous vasodilation by oral contraceptive hormones. J Appl Physiol 1997; 83: 2012-8. https://doi.org/10.1152 /jappl.1997.83.6.2012

Charkoudian N, Johnson JM. Reflex control of cutaneous vasoconstrictor system is reset by exogenous female reproductive hormones. J Appl Physiol 1999b; 87:3815. https://doi.org/10.1152/jappl.1999.87.1.381

Cowburn AS, Macias D, Summers C, Chilvers ER, Johnson RS. Cardiovascular adaptation to hypoxia and the role of peripheral resistance. Elife 2017; 6: e28755. https://doi.org/10.7554/eLife.28755

Degroot DW, Kenney WL. Impaired defense of core temperature in aged humans during mild cold stress. Am J Physiol Regul Integr Comp Physiol 2007; 292: R103-8. https://doi.org/10.1152/ajpregu.00074.2006

Dejima Y, Fukuda S, Ichijoh Y, Takasaka K, Ohtsuka R. 
Cold-induced salt intake in mice and catecholamine, renin and thermogenesis mechanisms. Appetite 1996; 26: 203-19. https://doi.org/10.1006/appe.1996.0016

Dias AC, Vitela M, Colombari E, Mifflin SW. Nitric oxide modulation of glutamatergic, baroreflex, and cardiopulmonary transmission in the nucleus of the solitary tract. Am J Physiol Heart Circ Physio 2005; 288: H256-62. https://doi.org/10.1152/ajpheart.01149.2003

Dias MB, Nucci TB, Margatho LO, Antunes-Rodrigues J, Gargaglioni LH, Branco LGS. Raphe magnus nucleus is involved in ventilatory but not hypothermic response to CO2. J Appl Physiol 2007; 103: 1780-8. https://doi.org/ 10.1152/japplphysiol.00424.2007

Dickenson $\mathrm{AH}$. Specific responses of rat raphe neurones to skin temperature. J Physiol 1977; 273: 277-93. https://doi.org/10.1113/jphysiol.1977.sp012094

D'yakonova T. NO-producing compounds transform neuron responses to glutamate. Neurosci Behav Physiol 2000; 30: 153-59.

Edholm OG, Fox RH, Macpherson RK. Vasomotor control of the cutaneous blood vessels in the human forearm. J Physiol 1957; 139: 455-65. https://doi.org/10.1113 /jphysiol.1957.sp005904

Eriksson S, Hjelmqvist H, Keil R, Gerstberger Rd. Central application of a nitric oxide donor activates heat defense in the rabbit. Brain Res 1997; 774: 269-73. https://doi.org/10.1016/S0006-8993(97)81719-2

Eyolfson DA, Tikuisis P, Xu X, Weseen G, Giesbrecht GG. Measurement and prediction of peak shivering intensity in humans. Eur J Appl Physiol 2001; 84: 100-6. https://doi.org/10.1007/s004210000329

Greaney JL, Kenney WL, Alexander LM. Neurovascular mechanisms underlying augmented cold-induced reflex cutaneous vasoconstriction in human hypertension. J physiol 2017; 595: 1687-98. https://doi.org/10.1113/ JP273487

Hiramatsu K, Yamada T, Katsura M. Acute effects of cold on blood pressure, renin-angiotensin-aldosterone system, catecholamines and adrenal steroids in man. Clin Exp Pharmacol Physiol 1984; 11: 171-9. https://doi.org/10.1111/j.1440-1681.1984.tb00254.x

Johnson JM. Exercise and the cutaneous circulation. Exerc Sport Sci Rev 1992; 20: 59-97. https://doi.org/10.1249/ 00003677-199200200-00003

Johnson JM, Brengelmann GL, Hales JR, Vanhoutte PM, Wenger CB. Regulation of the cutaneous circulation. Fed Proc 1986a; 45: 2841-50.

Johnson JM, O'Leary DS, Taylor WF, Kosiba W. Effect of local warming on forearm reactive hyperaemia. Clin Physiol 1986b; 6: 337-46. https://doi.org/10.1111 j.1475-097X.1986.tb00239.x

Johnson JM, Proppe DW. Cardiovascular adjustments to heat stress. In: Handbook of Physiology. Fregly MI, Blatteis CM, eds. Section 4: Environmental physiology. New York, NY: Oxford University Press, 1996, P. 21543.

Johnson JM, Taylor WF, Shepherd AP, Park MA. LaserDoppler measurement of skin blood flow: comparison with plethysmography. J Appl Physiol Respir Environ
Exerc Physiol 1984; 56: 798-803. https://doi.org/ 10.1152/jappl.1984.56.3.798

Johnson KB, Wiesmann WP, Pearce FJ. The effect of hypothermia on potassium and glucose changes in isobaric hemorrhagic shock in the rat. Shock 1996; 6: 223-9. https://doi.org/10.1097/00024382-199609010-00012

Kao CH, Chio CC, Lin MT, Yeh $\mathrm{CH}$. Body cooling ameliorating spinal cord injury may be neurogenesis-, anti-inflammation-and angiogenesis-associated in rats. J Trauma 2011; 70: 885-93. https://doi.org/10.1097/ TA.0b013e3181e7456d

Kellogg DL Jr, Crandall CG, Liu Y, Charkoudian N, Johnson JM. Nitric oxide and cutaneous active vasodilation during heat stress in humans. J Appl Physiol 1998; 85: 824-9. https://doi.org/10.1152/jappl.1998.85.3.824

Kellogg DL Jr, Liu Y, Kosiba IF, Kosiba IF, O'Donnell D. Role of nitric oxide in the vascular effects of local warming of the skin in humans. J Appl Physiol 1999; 86: 1185-90. https://doi.org/10.1152/jappl.1999.86.4.1185

Kenney WL, Craighead DH, Alexander LM. Heat waves, aging, and human cardiovascular health. Med Sci Sports Exerc 2014; 46: 1891-9. https://doi.org/10.1249/ MSS.0000000000000325

Key BJ, Wigfield CC. Changes in the tail surface temperature of the rat following injection of 5hydroxytryptamine into the ventrolateral medulla. Neuropharmacology 1992; 31: 717-23. https://doi.org/ 10.1016/0028-3908(92)90032-K

Klingenspor M. Cold-induced recruitment of brown adipose tissue thermogenesis. Exp Physiol 2003; 88: 141-8. https://doi.org/10.1113/eph8802508

Korsak A, Gilbey MP. Rostral ventromedial medulla and the control of cutaneous vasoconstrictor activity following icv prostaglandin E 1. Neurosci 2004; 124: 709-17. https://doi.org/10.1016/j.neuroscience.2003.12.019

Kourosh AM, Khameneh S, Zarghami N, Vahabian M. The effect of moderate hypothermia on renin-angiotensinaldosterone system in male rats. Int $\mathrm{J}$ Endocrinol Metab 2005; 3: 111-5.

Kourosh AM, Sarihi A, Behzadi G, Amiri I, Malacoti S, Vahabian M. The effect of nucleus tractus solitarius nitric oxidergic neurons on blood pressure in diabetic rats. Iran Biomed J 2006; 10: 15-9.

Kourosh Arami M, Semnanian S, Javan M, Hajizadeh S, Sarihi A. Postnatal developmental alterations in the locus coeruleus neuronal fast excitatory postsynaptic currents mediated by ionotropic glutamate receptors of rat. Physiology and Pharmacology 2011; 14: 338-348.

Kuo JR, Lo CJ, Chang CP, Lin HJ, Lin MT, Chio CC. Brain cooling-stimulated angiogenesis and neurogenesis attenuated traumatic brain injury in rats. J Trauma 2010; 69: 1467-72. https://doi.org/10.1097/TA.0b013e3181f31 b06

Lee $\mathrm{JH}$. The $\mathrm{Na} / \mathrm{K}$ pump, resting potential and selective permeability in canine Purkinje fibres at physiologic and room temperatures. Experientia 1996; 52: 560-657. https://doi.org/10.1007/BF01925568

Leger L, Charnay Y, Burlet S, Gay N, Schaad N, Bouras C, 
et al. Comparative distribution of nitric oxide synthaseand serotonin-containing neurons in the raphe nuclei of four mammalian species. Histochem Cell Biol 1998; 110: 517-25. https://doi.org/10.1007/s004180050313

Lossius K, Eriksen M, Walloe L. Fluctuations in blood flow to acral skin in humans: connection with heart rate and blood pressure variability. J Physiol 1993; 460: 641-55. https://doi.org/10.1113/jphysiol.1993.sp019491

MacKenzie MA, Wollersheim HC, Lenders JW, Hermus AR, Thien T. Skin blood flow and autonomic reactivity in human poikilothermia. Clin Auton Res 1996; 6: 91-7. https://doi.org/10.1007/BF02291229

Malakouti SM, Kourosh Arami M, Sarihi A, Hajizadeh S, Behzadi G, Shahidi S, et al. Reversible inactivation and excitation of nucleus raphe magnus can modulate tail blood flow of male wistar rats in response to hypothermia. Iran Biomed J 2008; 12: 203-208.

Mathai ML, Arnold I, Febbraio MA, McKinley MJ. Central blockade of nitric oxide synthesis induces hyperthermia that is prevented by indomethacin in rats. $\mathrm{J}$ Therm Biol 2004; 29: 401-5. https://doi.org/10.1016/j.jtherbio. 2004.08.005

Messina G, Dalia C, Tafuri D, Monda V, Palmieri F, Dato A, et al. Orexin-A controls sympathetic activity and eating behavior.Front Psychol 2014; 5: 997. https://doi.org/10.3389/fpsyg.2014.00997.

Nakamura K, Matsumura K, Hübschle T, Nakamura Y, Hioki $H$, Fujiyama $F$, et al. Identification of sympathetic premotor neurons in medullary raphe regions mediating fever and other thermoregulatory functions. J Neurosci 2004; 24: 5370-80. https://doi.org/10.1523/ JNEUROSCI.1219-04.2004

Nalivaiko E, Blessing WW. Potential role of medullary raphe-spinal neurons in cutaneous vasoconstriction: an in vivo electrophysiological study. J Neurophysiol 2002; 87: 901-11. https://doi.org/10.1152/jn.00221.2001

Nedergaard J, Bengtsson T, Cannon B. Unexpected evidence for active brown adipose tissue in adult humans. Am J Physiol Endocrinol Metab 2007; 293: E444-52. https://doi.org/10.1152/ajpendo.00691.2006

Oberg PA. Laser-Doppler flowmetry. Crit Rev Biomed Eng 1990; 18: 125-63.

Pergola PE, Kellogg DL Jr, Johnson JM, Kosiba WA. Reflex control of active cutaneous vasodilation by skin temperature in humans. Am J Physiol 1994; 266: H1979-84. https://doi.org/10.1152/ajpheart.1994.266.5. H1979

Ramasamy SK, Kusumbe AP, Schiller M, Zeuschner D, Bixel MG, Milia C, et al. Blood flow controls bone vascular function and osteogenesis. Nat Commun 2016; 7: 13601. https://doi.org/10.1038/ncomms13601

Rathner JA, McAllen RM. Differential control of sympathetic drive to the rat tail artery and kidney by medullary premotor cell groups. Brain Res 1999; 834: 196-9. https://doi.org/10.1016/S0006-8993(99)01568-1

Rezaei Z, Kourosh-Arami M, Azizi H, Semnanian S. Orexin type-1 receptor inhibition in the rat lateral paragigantocellularis nucleus attenuates development of morphine dependence. Neurosci Lett 2020; 27:
134875. https://doi.org/10.1016/j.neulet.2020.134875

Rendell MS, Milliken BK, Banset EJ, Finnegan M, Stanosheck C, Terando JV. The effect of chronic hypertension on skin blood flow. J hypertens 1996; 14 : 609-14. https://doi.org/10.1097/00004872-19960500000010

Roberts MF, Wenger CB, Stolwijlc JA, Nadel ER. Skin blood flow and sweating changes following exercise training and heat acclimation. J Appl Physiol Respir Environ Exerc Physiol 1977; 43: 133-7. https://doi.org/ 10.1152/jappl.1977.43.1.133

Romanovsky AA. Thermoregulation: some concepts have changed. Functional architecture of the thermoregulatory system. Am J Physiol Regul Integr Comp Physiol 2007; 292: R37-46. https://doi.org/ 10.1152/ajpregu.00668.2006

Saito M, Okamatsu-Ogura Y, Matsushita M, Watanabe K, Yoneshiro T, Nio-Kobayashi J, et al. High incidence of metabolically active brown adipose tissue in healthy adult humans: effects of cold exposure and adiposity. Diabetes 2009; 58: 1526-31. https://doi.org/10.2337/ db09-0530

Saumet JL, Kellogg DL Jr, Taylor WF, Johnson JM. Cutaneous laser-Doppler flowmetry: influence of underlying muscle blood flow. J Appl Physiol 1988; 65: 478-81. https://doi.org/10.1152/jappl.1988.65.1.478

Semenza JC, McCullough JE, Flanders WD, McGeehin MA, Lumpkin JR. Excess hospital admissions during the July 1995 heat wave in Chicago. Am J Prev Med 1999; 16: 269-77. https://doi.org/10.1016/S0749-3797(99) 00025-2

Shahidi M, Vatanmakanian M, Arami MK, Sadeghi Shirazi F, Esmaeili N, Hydarporian S, et al. A comparative study between platelet-rich plasma and platelet-poor plasma effects on angiogenesis. Med Mol Morphol 2018; 51: 21-31. https://doi.org/10.1007/s00795-0170168-5

Smith CJ, Johnson JM. Responses to hyperthermia. Optimizing heat dissipation by convection and evaporation: neural control of skin blood flow and sweating in humans. Auton Neurosci 2016; 196: 25-36. https://doi.org/10.1016/j.autneu.2016.01.002

Smith JE, Gilbey MP. Segmental origin of sympathetic preganglionic neurones regulating the tail circulation in the rat. J Auton Nerv Syst 1998; 68: 109-14. https://doi.org/10.1016/S0165-1838(97)00124-0

Stephens DP, Aoki K, Kosiba WA, Johnson JM. Nonnoradrenergic mechanism of reflex cutaneous vasoconstriction in men. Am J Physiol Heart Circ Physiol 2001; 280: H1496-504. https://doi.org/10.1152/ ajpheart.2001.280.4.H1496

Stephens DP, Bennett LAT, Aoki K, Kosiba WA, Charkoudian N, Johnson JM. Sympathetic nonnoradrenergic cutaneous vasoconstriction in women is associated with reproductive hormone status. Am J Physiol Heart Circ Physiol 2002; 282: H264-72. https://doi.org/10.1152/ajpheart.2002.282.1.H264

Stephens DP, Saad AR, Bennett LA, Kosiba WA, Johnson JM. Neuropeptide $Y$ antagonism reduces reflex 
cutaneous vasoconstriction in humans. Am J PhysiolHeart Circ Physiol 2004; 287: H1404-9. https://doi.org/ 10.1152/ajpheart.00061.2004

Stephenson LA, Kolka MA. Menstrual cycle phase and time of day alter reference signal controlling arm blood flow and sweating. Am J Physiol 1985; 249: R186-91. https://doi.org/10.1152/ajpregu.1985.249.2.R186

Stern L. Thermoregulation in the newborn infant: historical, physiological and clinical considerations. In: George F, Smith MD, Dharmapuri vidyasagar. Historical Review and Recent Advances in Neonatal and Perinatal Medicine 1980, P. 35-6.

Sun Z, Cade JR, Fregly MJ. Cold-induced hypertension. Ann N Y Acad of Sci 1997; 813: 682-8. https://doi.org/ 10.1111/j.1749-6632.1997.tb51767.x

Talwar A, Fahim M. Detrimental effect of hypothermia during acute normovolaemic haemodilution in anaesthetized cats. Int $\mathrm{J}$ biometeorol 1998; 41: 113-9. https://doi.org/10.1007/s004840050062

Tanaka M, Nagashima K, McAllen RM, Kanosue K. Role of the medullary raphe in thermoregulatory vasomotor control in rats. J Physiol 2002; 540: 657-64. https://doi.org/10.1113/jphysiol.2001.012989

Tansey EA, Johnson CD. Recent advances in thermoregulation. Adv Physiol Educ 2015; 39: 139-48. https://doi.org/10.1152/advan.00126.2014

Taylor NA, Machado-Moreira CA, van den Heuvel AM, Caldwell JN. Hands and feet: physiological insulators, radiators and evaporators. Eur J Appl Physiol 2014; 114: 2037-60. https://doi.org/10.1007/s00421-014-29408

van der Lans AA, Hoeks J, Brans B, Vijgen GH, Visser MG, Vosselman $\mathrm{MJ}$, et al. Cold acclimation recruits human brown fat and increases nonshivering thermogenesis. J Clin invest 2013; 123: 3395-403. https://doi.org/ 10.1172/JCl68993

Van Poucke S, Stevens K, Marcus AE, Lancé $M$. Hypothermia: effects on platelet function and hemostasis. Thromb J 2014; 12: 31. https://doi.org/ 10.1186/s12959-014-0031-z

Xie YC, Li CY, Li T, et al. Effect of mild hypothermia on angiogenesis in rats with focal cerebral ischemia. Neurosci lett 2007; 422: 87-90. https://doi.org/10.1016/ j.neulet.2007.03.072 